https://doi.org/10.48009/2_iis_2006_129-133

\title{
APPLICATION OF AN INFORMATION LANDSCAPE MODEL TO ANALYZE INFORMATION FLOWS IN A COMMUNITY OF PRACTICE
}

\author{
Larry George, Robert Morris University, lxgst3@rmu.edu \\ Robert Joseph Skovira, Robert Morris University, rjskovira@att.net
}

\begin{abstract}
This essay examines cultural and structural patterns of information use in a virtual meeting. An information landscape model provided an abductive approach for guiding ethnographic data collection acquired through participant observation. A political frame of information use was applied to analyze field data. The themes that emerged from the ethnographic componential analysis were governance and motivations for participating in the virtual meeting.
\end{abstract}

$\begin{array}{lllr}\text { Keywords: } & \begin{array}{l}\text { Information } \\ \text { Governance, }\end{array} & \begin{array}{l}\text { Technology } \\ \text { Virtual }\end{array} & \begin{array}{r}\text { (IT), } \\ \text { Meeting, }\end{array} \\ \text { Information } & \end{array}$

\section{INTRODUCTION}

The flow of information within organizations is both complex and critical. Whether for executive decisionmaking, execution of tasks, or connecting the two, information must be timely, accurate, and in a usable form. In today's competitive global environment, businesses must leverage information and the knowledge obtained from it not merely as a means of connecting components, but as a resource which can provide competitive advantage [23]. The need for information to move within geographically dispersed organizations is not a new phenomenon; Harris [as cited in 1], for example, has described how $16^{\text {th }}$ century European corporations developed sophisticated global information networks. The complexity of today's information flows is not simply the replacement of sailing ships by satellite communications, but is tied to the pace of change, the velocity of the flow, and the interface of organizational culture to information technology. [4]

In this paper we take an ethnographic field approach to understanding information situations. The specific situation of information use is a virtual, computermediated telephone conference.

\section{THEORETICAL BACKGROUND}

Virtual meetings have become a mainstay of business operations [7, 22], particularly for geographically dispersed organizations. This form of interaction supports a variety of activities, including recurring meetings ("staff meetings"), functional committee meetings (review of candidate research projects), and project teams (a new product design team) [3]. In general, virtual meetings have benefits, including fiscal (reduction of travel cost), efficiency (bringing together the most qualified individuals to focus on a problem), and practicality (geographically dispersed entities). Virtual meetings have drawbacks, however, some technological (IT), but more often cultural and contextual: development and maintenance of trust, lack of visual cues for speakers, misinterpretations of silence $[4,7]$. Research on virtual meetings $[1,3,7$, $11,16,15,17]$ has identified process dynamics and characteristics which are helpful in analyzing this information situation. Wasson [22] conducted an extensive study of virtual meetings in a hightechnology company using an ethnographic approach that included participant observation, interviews and video recording of participants. The focus of this effort was participant behavior during the meeting sessions, specifically multitasking activities.

The concept of virtual meetings also supports the activities of communities of practice, which Wenger [24] has defined as "social structures that focus on knowledge and explicitly enable the management of knowledge to be placed in the hands of the practitioners." Such communities of practice are frequently mentioned in the literature as a key element of knowledge management in organizations [5, 8, 24]. Lee [14] has examined "communities of interest," that form "to collaborate to gain insights and accelerate problem solving as well as to drive reusable knowledge within their areas of expertise." These communities involve individuals, cultures, technologies, and information, brought together in structured and unstructured forms, which complicate their analysis.

A variety of analytical approaches $[1,11,15,17]$ have been applied to obtain a better understanding of communities within organizations, typically in the form of a model which blends quantitative (volume of traffic, types of technologies available) and qualitative (cognitive, social, cultural) aspects, what one author described as "sociotechnical analysis" [2]. These approaches have been useful with established 
communities or virtual work teams focused on a particular objectives, but emerging communities or communities of interest with a high degree of ambiguity may require additional perspectives. Understanding such groups is important because the nascent community presents the best opportunity for an organization to facilitate their growth and channel their direction.

\section{Information Landscape}

Skovira [19] has described an abductive research approach which specified an information landscape model to guide ethnographic fieldwork. The model includes frames of information use and cultural dimensions and was subsequently applied to an investigation of stress management of Slovak IT professionals [18]. Frames of information use (political, financial legal, ethical, technological) are a means of understanding information use and design $[10,19]$. The political frame of use is about authority over information flows. And includes modes of information governance: technocratic utopianism, anarchy, feudalism, monarchy, and federalism [6]. Frames provide a cultural context for the information situation and have dimensions [13, 19].

Dimensions of culture (power distance, individualism-collectivism, masculinity-femininity, and uncertainty avoidance) applied to this situation are described in Hofstede and Hofstede [13]. Uncertainty avoidance is "the extent to which the members of a culture feel threatened by ambiguous or uncertain situations." The power distance dimension considers the degree of acceptance of power inequalities by subordinates and superiors. The masculinity-femininity dimension of a cultural situation examines whether the group is focused on achievement and performance or on well-being of the group. Individualism-collectivism refers to the degree to which a cultural situation is self- or group oriented.

Hall [12]) describes the uses of time and space to convey information. Cultures and cultural situations may be either monochronic (typical of Western cultures) or polychronic (Latin American and Middle Eastern countries). Monochronic cultures view time as linear and tangible. Polychronic cultures multi-task and are not schedule-driven.

Space and the use of space also provide context in cultural situations [12]. The size or location of an office, the objects in a space and their arrangement, whether the space is public or private all communicate information symbolically. Wasson [22] expanded Goffman's definition of meetings as "interactions with a central situational focus" [9] with the concept of "interactional spaces" [22]. Interactional spaces are communication zones in which individuals may interact, and may be physical or virtual. Other conceptual models on the use of space include Amin and Cohendet's "geographies of knowledge formation" [1] and Nonaka \& Konno's ba as a "shared space for emerging relationships" [17].

\section{Research Questions}

The research question is about cultural and structural patterns of information use in an informal information sharing group. A weekly telephone conference (or "telecon" in the native language of the group) on the subject of "horizontal integration" (HI) was provisionally deemed a situation of information use [19], with stable and enduring meanings shared. Following initial observations an abductive hypothesis was developed that identified the key issues in this situation as governance, power, and uncertainty. Research questions were formulated as guides for the detailed observation and analysis.
RQ1: Why do people join this non-mandatory meeting?
RQ2: What governance processes operate in this informal group?
RQ3: What do people do during the meetings: participate, listen, multi-task?

\section{METHOD}

The external setting for this information situation was a geographically-dispersed, technically-oriented company (a major business unit of a large corporation). The company has two missions as an organization. First is to provide information systems development and integration of large, complex systems. To meet this goal, the company is organized into lines of business focused on specific large customers or in some cases on a functional capability (systems integration). The second role is to serve as a "horizontal integrator" across all business units of the corporation to develop integrated solutions for customers that draw on all strengths and capabilities of the corporation.

The meeting was scheduled to occur from 1 to 2 p.m. (Eastern Time) every Thursday, using a commercial teleconference service. The call-in telephone number and the access code remained consistent from week to week, allowing the host to publish an annual meeting notice via Microsoft Outlook (the corporate enterprise application) which (a) sends a meeting notice via email (which the recipient may accept, 
tentatively accept or decline) to the community of interest and (b) populates their electronic calendars with the weekly meetings unless the recipient declines. The host typically sent an updated meeting notice each week to announce the specific topics (or to cancel for that week).

In addition to the verbal component of the teleconference, the meeting participants share briefing materials via Windows NetMeeting. Typically the teleconference members link in to the host, who then controls the view of the materials (typically PowerPoint charts, but anything that can reside on the host's Window's desktop can be shared. Participants also had access to a website portal which provided a collaboration environment and a knowledge repository for the community.

Participation was voluntary. During the period observed (August 11, 2005 through November 17, 2005), 107 different individuals participated in at least one session. Total participation in the 12 sessions August through November was 222; calculated mean attendance was 18.5 per session. An interview with the meeting host yielded four categories of participants: the host's staff, the "information hungry," those "tuning in," and those that did not normally participate, but whose participation "increases everyone's understanding." These emic categories were operationalized as follows: "information hungry" participated in four or more sessions; "tuning in" participated in two or three sessions; "understanding enhancers" attended one session.

The approach taken here was to extend the metaphor of information "flowing" through an organization. The confluence of virtual meeting practices and knowledge management structures in an organization may shape an "information landscape," whose analysis reveals information situations as "a nexus of information flows" [19]. The information landscape model was used to guide the data collection for the information situation. A political frame of information use [19] was appropriate for examining this information situation since the abductive hypothesis postulated issues of governance, power, and uncertainty.

The ethnographic field work was principally through participant observation [20] conducted during the weekly telecon, supplemented by unstructured discussions with the telecon host and selected participants. The observer was a regular participant in the group. Thus, the observations and ethnographic analysis provide an emic (or insider's) view of the information situation. Componential analysis of the field data produced themes which were then viewed through frames of information use [19, 24] to develop an etic (external) perspective of the situation.

\section{RESULTS}

Although designed to be a collaborative exercise in information sharing, initial observations pointed to clear governance and authority exercised by the host. Thus, a political frame of information use was appropriate. The participants were in or affiliated with horizontal integration, which, as previously described, was a new endeavor within the company and in the customer community. Goals, roles, and authority were unclear to many. Thus, ambiguity and uncertainty were also potentially important factors.

Inside the company and the corporation writ large, the term "horizontal integration" is less a wellunderstood category than a term of art. Given the "newness" of HI, the individuals now tasked to "do HI" struggled with questions of exactly what they were supposed to do. An informal group of interested individuals coalesced around the subject area and began to share knowledge across the business unit in a virtual collaboration via a telephone conference. These observations indicated that uncertainty avoidance [13] (through information seeking via the telecon) was an important element in the information landscape, particularly in the context of research question (2).

With the exception of the host's staff, there was no direct organizational power relationship between the host and the participants. This lack of formal relationships and the anonymity individuals enjoy in a virtual meeting could lead to an "anarchical" mode of information governance. The fact that "anarchy" was not observed and Wenger's observations on the key role of facilitators in communities of practice [24] led to a more detailed focus on the host's role and to a key finding: The host exercised power over the telecon through processes and technology that facilitated control over the information flows.

Prior to the meetings, the host set the telecon topic, thus bounding the nature of the information presented. During the telecon itself, the host used verbal techniques to control the flow of the meeting. These included asking clarifying questions, requesting the speaker to spell out acronyms, or providing embellishing remarks. The flow of visual materials was also controlled by using the host's computer as the NetMeeting hub. Through these techniques the host converted a potentially anarchical 
form of information governance into a monarchial form. This power inequality was accepted by the other participants, a conclusion based on the consistent attendance levels and the number of repeat participants.

The telecon's strict adherence to a precise start time and a one hour limit (reflective of the monochronic, schedule-driven company culture) demonstrated concern with the scarcity of this precious resource (time) among the participants. As one of the "information hungry" participants noted, "I can afford an hour." There was also a goal of inclusion, a "many-to-many" approach through inviting personnel from the lines of business, staff functions, and horizontal integration. Thus, the dominant characteristic in this cultural dimension was femininity, with an emphasis on the well-being of the participants. This factor helps explain why the participants allowed the monarchial form of information governance-it could be viewed as a "benign" monarchy.

The host had a collectivist vision for the telecon. A "key engagement objective" for example was to develop a "broader set of HI advocates that can carry the HI message." An analysis of the emic category labels, however, pointed to an individualistic orientation. People participated to gain information (either as "hungry" consumers or just "tuning in"). Unlike virtual project teams $[4,7,15]$ the telecon had no required output: the participants were not focused on achieving a tangible objective (designing a new airplane, for example). Rather it was a looselydefined community of individuals with a shared interest in (and uncertainty about) HI.

The virtual nature of the meeting also contributed to the individualistic orientation. Participation was an individual decision, and as Wasson [22] notes, virtual participants have a degree of anonymity that yields greater individual freedom of action. Under the concept of "interactional spaces" the participants are simultaneously in at least two spaces, one virtual (the telecon information situation) and one local (the individual's office). Many of the participants she observed were multitasking. The HI telecon was very monochronic, as noted above, but multitasking by individual participants could produce a polychronic culture [12].

\section{RECOMMENDATIONS FOR FUTURE RESEARCH}

Further research would involve structured interviews with a representative sample from each of the categories of participant, direct observation of individuals during the telecon, and additional exploration of the temporal-spatial aspects of information flow. The interaction of the cultural aspects of space and time in virtual meetings is a promising avenue for additional research, using the information landscape model in conjunction with other conceptual models such as Wasson's “interactional spaces" [22], Nonaka \& Konno's ba as a "shared space for emerging relationships" [17] and Amin \& Cohendet's "spaces of knowing" [1].

Participant observation had one drawback in the context of the study. It was not practical to participate in the telecon, conduct observations of the information flow, and physically observe other, geographically-dispersed participants. Thus, research question RQ3 was not addressed. Wasson [22] overcame this difficulty by video taping participants for later analysis of simultaneous activities. Such access is not likely to be granted for this information situation, but sequential observation could provide the data to address the unanswered research question.

\section{CONCLUSION}

The research question considered was about cultural and structural patterns of information use in an informal information sharing group. Consistent with the research questions derived from the model, the themes that emerged from the ethnographic domain analysis were motivations for participating in this voluntary group (RQ1) and information governance (RQ2). The model also provided additional contextual information along other cultural dimensions. The question of how participants spent their time during the telecon could not be addressed in the present effort due to the realities of the virtual meeting.

The information landscape model proved to be an effective approach that yielded insights into the dynamics of an emerging community of interest. The application of frames of information use coupled with ethnographic field techniques produced a rich understanding of the interaction of people, processes, and technology.

\section{REFERENCES}

1. Amin, A. \& Cohendet, P. (2005). Geographies of knowledge formation in firms. Industry and Innovation, 12(4), 465-486. Retrieved March 2, 2006, from ABI/INFORM Global.

2. Cai, J. (2006).Knowledge formation within collaborative processes: A perspective modeling 
and analyzing methodology. Journal of Database Management, 17(1), 33-48. Retrieved March 2, 2006, from ABI/INFORM Global.

3. Cascio, W. F. (2000). Managing a virtual workplace. The Academy of Management Executive, 14(3), 81-90. Retrieved November 24, 2005, from ABI/INFORM Global.

4. Cramton, C. D. (2001). The mutual knowledge problem and its consequences for dispersed collaboration. Organization Science, 12(3), 346371. Retrieved November 25, 2005, from ABI/INFORM Global.

5. Cummings, J. N. (2004). Work groups, structural diversity, and knowledge sharing in a global organization. Management Science, 50(3), 352364. Retrieved November 24, 2005, from ABI/INFORM Global.

6. Davenport, T. H., Eccles, R. G., \& Prusak, L. (1992). Information politics. Sloan Management Review, 34(1), 53. Retrieved November 25, 2005, from ABI/INFORM Global.

7. Davenport, T. H. \& Pearlson, K. (1998). Two cheers for the virtual office. Sloan Management Review, 39(4), 51-65. Retrieved November 25, 2005, from ABI/INFORM Global.

8. Davenport, T. H. \& Volpel, S. C. (2001). The rise of knowledge towards attention management. Journal of Knowledge Management, 5(3), 212-221. Retrieved November 25, 2005, from ABI/INFORM Global.

9. Goffman, E. (1963). Behavior in public places: notes on the social organization of gatherings. New York: Free Press.

10. Goffman, E. (1974). Frame analysis: an essay on the organization of experience. Cambridge, MA: Harvard University Press.

11. Grossman, M. (2006). An overview of knowledge management assessment approaches. Journal of American Academy of Business, Cambridge, 8(2), 242-247. Retrieved March 2, 2006, from ABI/INFORM Global.

12. Hall, E. T. (1989). Beyond culture. New York: Anchor Books.

13. Hofsted, G. \& Hofstede, G. J. (2005). Cultures and organizations: software of the mind. New York: McGraw-Hill.
14. Lee Sr., J. (2000). Knowledge management: the intellectual revolution. IIE Solutions, 32(10), 3437. Retrieved November 25, 2005, from ABI/INFORM Global.

15. Manzevski, M. L. \& Chudoba, K. M. (2000). Bridging space over time: global virtual team dynamics and effectiveness. Organization Science, 11(5), 473-492. Retrieved November 24, 2005, from ABI/INFORM Global.

16. Mittleman, D. D., Briggs, R. O., \& Nunamaker Jr, J. F. (2000). Best practices in facilitating virtual meetings: Some notes from initial experience. Group Facilitation, 2(2), 5. Retrieved November 24, 2005, from ABI/INFORM Global.

17. Nonaka, I. \& Konno, N. (1998). The concept of "ba": Building a foundation for knowledge creation. California Management Review, 40 (3), 40-54. Retrieved March 2, 2006, from ABI/INFORM Global.

18. Skovira, R. J. (2005). Specifying an idea for inquiry about uncertainty avoidance models among Slovak IT professional in the information society. Proceedings of INFOS 2005, Bratislava, 141-148.

19. Skovira, R. J. (2004). Using informational landscape as a model to understand information use and design within organizations. Issues in Information Systems, V (1), 308-314.

20. Spradley, J. P. (1980). Participant observation. New York: Wadsworth Thomson Learning.

21. Simon, H. A. (1969). The sciences of the artificial. Cambridge, MA: The M.I.T. Press.

22. Wasson, C. (2004) Multitasking during virtual meetings. Human Resource Planning. 27(4). Retrieved from ABI/INFORM Global.

23. Wenger, E. (1996). Communities of practice: the social fabric of a learning organization. The Healthcare Forum Journal, 39(4), 20. Retrieved November 25, 2005, from ABI/INFORM Global.

24. Wenger, E., McDermott, R., \& Snyder, W. M. (2002). Cultivating communities of practice: $A$ guide to managing knowledge. Harvard Business School Publications: Boston. 